Philosophy and Progress: Vols. LI-LII, January-June, July-December, 2012 ISSN 1607-2278 (Print), DOI : http://dx.doi.org/10.3329/pp.v51i1-2.17681

\section{THE LINGUISTIC PHILOSOPHY OF NOAM CHOMSKY}

\section{Binoy Barman*}

\begin{abstract}
Noam Chomsky, one of the most famous linguists of the twentieth century, based his linguistic works on certain philosophical doctrines. His main contribution to linguistics is Transformational Generative Grammar, which is founded on mentalist philosophy. He opposes the behaviourist psychology in favour of innatism for explaining the acquisition of language. He claims that it becomes possible for human child to learn a language for the linguistic faculty with which the child is born, and that the use of language for an adult is mostly a mental exercise. His ideas brought about a revolution in linguistics, dubbed as Chomskyan Revolution. According to him, the part of language which is innate to human being would be called Universal Grammar. His philosophy holds a strong propensity to rationalism in search of a cognitive foundation. His theory is a continuation of analytic philosophy, which puts language in the centre of philosophical investigation. He would also be identified as
\end{abstract}

\footnotetext{
* Director, Daffodil Institute of Languages, \& Associate Professor, Department of English, Daffodil International University

E-mail : drbinoy@daffodilvarsity.edu.bd
}

an essentialist. This paper considers various aspects of Chomsky's linguistic philosophy with necessary elaborations.

Key words: Transformational generative grammar, universal grammar, behaviourism, innatism, Chomskyan hierarchy, analytic philosophy, essentialism, parameter setting, language acquisition device, critical period hypothesis, cognitive psychology, linguistic nativism, reductionism.

\section{Introduction:}

Noam Chomsky is one of the most influential linguists of the twentieth century and still today he dominates the scene of theoretical linguistics. He is most famous for his unique linguistic philosophy. He has revolutionised the discipline of linguistics with his much-talked-about theory of Transformational Generative Grammar (TGG), in which he emphasises the mental capacity of generating sentences with the use of unconscious knowledge of language which he calls Universal Grammar (UG). He says, TGG attempts to specify 'what the speaker actually knows' (Chomsky, 1965: 8). He asserts that human brain is biologically programmed to learn language, so language faculty is innate. For him, mind works during the course of learning a language. These innatist and mentalist views made his theory distinct, placing him in headon collision with behaviourism, which was much in fashion during the first half of the twentieth century. Chomsky dealt a serious blow to behaviourism, after which stimulus-response theory of language learning was abandoned, giving a boost to cognitive psychology. This paradigm shift in the history of linguistics is recognised as Chomskyan Revolution. Chomsky's particular kind of philosophy is also known as Chomskyan Hierarchy. Neil Smith enumerates his distinctions in the following terms: 
He has revolutionised linguistics, and in so doing has set a cat among the philosophical pigeons. He has resurrected the theory of innate ideas, demonstrating that a substantial part of our knowledge is genetically determined; he has reinstated rationalist ideas that go back centuries, but which has fallen into disrepute; and he has provided evidences that unconscious knowledge is what underlies our ability to speak and understand. (Smith 1999: 1)

Chomskyan Hierarchy has been established through his continuous writing over a span of half a century. He has authored several seminal texts including Syntactic Structures (1957), Aspects of the Theory of Syntax (1965), Cartesian Linguistics (1966), Language and Mind (1968), The Logical Structure of Linguistic Theory (1975), Reflections on Language (1976), Language and Responsibility (1977), Lectures on Government and Binding (1982), Knowledge of Language: Its Nature, Origin and Use (1986), Language and Problems of Knowledge (1988), Language and Thought (1993), Language and the Problem of Knowledge (1994), The Minimalist Program (1995), The Architecture of Language (2000) and On Nature and Language (2002), which have contributed significantly to cognitive science through linguistics.

To Christopher Wise (2011), Chomsky's identity as a 'philosopher of language' has featured more prominently than that of a 'linguist'. William Lycan in his preface to Philosophy of Language: A Contemporary Introduction (2008) has observed that a crucial development in the past forty years is the attention of philosophers of language to formal grammar or syntax as articulated by theoretical linguists. Chomsky was in the vanguard of this development. He is still active in his writing. Just in 2012, he has written The Science of Language, in which he talks to James McGilvray, Professor of Philosophy at McGill University, covering such topics as the nature of language, the philosophies of language and mind, morality and universality, science and common sense, and the evolution of language.

Fred D'Agostino's book Chomsky's System of Ideas (1986) provides a detailed analysis of his philosophical doctrines. He has elaborated on how his individualism, mentalism, rationalism and intellectualism developed to challenge the existing theories and open new avenues of knowledge. It appears that Chomsky's linguistic philosophy has three main features. First, mind is cognitive, that is, it is the centre of thoughts, including those of language. Second, most of the important properties of language and mind are innate. Third, the mind is composed of an array of interacting and specialised subsystems, which make linguistic activities possible. The following discussion will cover Chomsky's ideas of linguistic philosophy vis-à-vis rationalist, analytic, cognitive, essentialist and reductionist properties.

\section{Chomsky's Rationalism:}

As a linguist, Noam Chomsky adheres to rationalism, in opposition to empiricism. His philosophy of language shows a clear influence of rationalistic ideology, which claims that reason or rationality as a property of mind is the primary source of knowledge or way to knowledge. His work is inspired by such philosophers as Plato, Rene Descartes, Baruch Spinoza, Gottfried Leibniz and Immanuel Kant. His theory is related to rationalist ideas of a priori knowledge, manifested in innatism and nativism. In the introduction to Modern Philosophy of Language, Maria Baghramian traces the history of influence: 
The history of philosophical concern with language is as old as philosophy itself. Plato in Cratylus explored the relationship between names and things and engaged in what today would be recognised as philosophy of language. Most philosophers since Plato have shown some interest in language. Rene Descartes (1596-1650), the founder father of modern philosophy, for instance, believed in the existence of universal language underpinning the diverse languages which human communities use and is seen by twentiethcentury linguist Noam Chomsky as a precursor of the theory of innateness of linguistic abilities.

As a self-declared Cartesian, Chomsky via Cartesian Linguistics (1966) clearly embraces the interpretation of Descartes' famous dictum 'I think therefore I am' (cogito ergo sum) as the solid foundation for knowledge. With this Cartesian spirit, Chomsky has provided a subjective view of language, claiming that language refers to certain mental states, which a linguistic theory will explicate. He says:

We should, so it appears, think of knowledge of language as a certain state of mind/brain, a relatively stable element in transitory mental states once it is attained; furthermore as a state of some distinguishable faculty of the mind - the language faculty - with its specific properties, structure and organisation, one module of the mind. (Chomsky, 1986: 1213)

Chomsky was also influenced by Kantian epistemology, which sought a synthesis of empiricism and rationalism. Kant's influence on Chomsky is laid down by Pinker:

Kant's version of nativism, with abstract categorising frameworks but not actual knowledge built into the mind, is the version that is most viable today, and can be found, for example, in Chomskyan linguistics, evolutionary psychology, and the approach to cognitive development called domain specificity. (Pinker, 2007: 160)

Chomsky's linguistic-philosophical formulations also owe much to the ideas of Plato and Leibniz. He recalls:

Much of the interest of the study of language, in my opinion, lies in the fact that it offers an approach to the classical problem that I call 'Plato's problem': the problem of explaining how we can know what we do know. Plato's answer was that much of what we know in inborn, remembered from an earlier existence. Leibniz argued that the idea is basically correct, but must be purged of the error of pre-existence. Much of our knowledge is innate, he held, virtually present in the mind even if not clearly articulated. (Chomsky, 1986: 263)

Recalls Chomsky argued that a serious theory of mental processes should replace empiricism, the belief that experience is the source of knowledge. Opposing empiricism, he says, 'In a sense, empiricism has developed a kind of mind-body dualism, of a quite unacceptable type .... empiricism insists that the brain is a tabula rasa, empty, unstructured .... There is no reason to believe that the higher mental faculties are in some manner dissociated from this complexity of organisation' (Chomsky, 1977: 81). He further states:

These empiricist hypotheses have very little plausibility, in my opinion; it does not seem possible to account for the development of commonsense understanding of the physical and social world, or science, in terms of processes of induction, generalisation, abstraction, and so on. There is no such direct path from data that are given to intelligible theories. (Chomsky, 1977: 68)

Given his characterisation of language as a system of knowledge - downplaying the significance of actual 
performance, emphasising the creative aspect of language use, endorsing innate principles of grammar and postulating structure invisible on the surface - Chomsky is rightly regarded as an heir to the rationalist tradition in the philosophy of language and mind. Chomsky (1966) himself emphasised his indebtedness to such a tradition, especially to the Port-Royal Grammar and to Humboldt.

But there are important aspects in which Chomsky's views are different from the rationalist picture. First of all, in speaking about linguistic competence, Chomsky is willing to consider a kind of knowledge which, although innate, is not exactly based on reason. Second, he does not think that UG bears any intrinsic relation to the structure of reality. Third, he rejects semantic theories that are based on truth and reference and consequently require the study of language-world relations. (Szabó, 2004)

\section{Analytic Philosophy:}

Chomsky's work happens to fall in the line of analytic philosophy, where logic and language are central to theorisation. Chomsky makes use of logic and mathematics in his linguistic analysis, yielding a distinct formal language. In TGG, Chomsky creates a small set of rules that can correctly generate all the combinations of words possible to form all the grammatical sentences of a language. He does this by using an algorithm to predict all grammatically correct sentences.

Chomsky's position among analytic philosophers has been respected due to three factors. First, Chomsky contributed substantially to a major methodological shift in the human sciences, turning away from the prevailing empiricism of mid twentieth century: behaviourism in psychology, structuralism in linguistics and positivism in philosophy. Second, his groundbreaking book Aspects of the Theory of Syntax (1965) laid a conceptual foundation for a new cognitivist approach to linguistics and provided philosophers with a new framework for exploring human language and mind. And finally, he has persistently defended his views, engaging in important debates with the major figures in analytic and critical philosophy including Tyler Burge, Donald Davidson, Michael Dummett, Saul Kripke, Thomas Nagel, Hilary Putnam, Willard Van Orman Quine, John Searle, Jacques Derrida, Michel Foucault and Julia Kristeva throughout his career. This debate literature is the evidence of his intellectualism.

The conceptual framework of Chomsky's early work on syntax has been extremely influential among philosophers. His distinction between deep and surface structure seemed to sit well with the tradition within analytic philosophy, going back to Russell's theory of descriptions, that the surface appearance of a sentence often masks its true structure. As shown in Aspects of the Theory of Syntax (1965), grammar is divided into two levels of representation: the deep structure, generated by the recursive rules of a context-free phrase structure grammar, and the surface structure, derived from the deep structure through the application of transformation rules. Much of the subsequent development of the theory in the 1970's can be viewed as a series of attempts to formulate constraints on both the generative and the transformational components. An example of the former is the development of X-bar theory, which specifies a common internal structural skeleton for all phrases; an example of the latter is the proposal to reduce the available movements to the single rule 'move alpha', whose applicability is then restricted by a few general constraints. 


\section{Cognitive Psychology:}

According to Chomsky, language is a natural object, a component of the human mind, physically represented in the brain and part of the biological endowment of the species (Chomsky, 2002: 1). As a pursuant of cognitivism, he criticised behaviourism, which seeks to understand behaviour and language as a function of environment or setting. He demonstrated its limitations. He claimed that many of the properties of language are innate so as to be found in deep structures of language, to which behaviourism has turned a blind eye.

In 1959 Chomsky published his critique of B. F. Skinner's Verbal Behaviour, a book in which Skinner offered a theoretical account of language in functional and behavioural terms. Skinner's approach stressed the circumstances in which language was used. Chomsky thought that a functionalist explanation restricting itself to communicative performance ignored important questions. He stated the view that the experimental data gathering techniques developed in the behavioural sciences are neither used nor needed in linguistic theorising:

The gathering of data is informal; there has been little use of experimental approaches (outside of phonetics) or of complex techniques of data collection and data analysis of a sort that can easily be devised, and that are widely used in the behavioural sciences. The arguments in favour of this informal procedure seem to me quite compelling; basically, they turn on the realisation that for the theoretical problems that seem most critical today, it is not at all difficult to obtain a mass of crucial data without use of such techniques. Consequently, linguistic work, at what I believe to be its best, lacks many of the features of the behavioural sciences. (Chomsky, 1969: 56)
Chomsky noted that the scientific application of behavioural principles from animal research is severely lacking in explanatory adequacy (Harrison 1979: 20). A theory restricting itself to external conditions cannot adequately account for generative grammar. Chomsky put forward the examples of rapid language acquisition of children, including their quickly developing ability to form grammatical sentences, and the universally creative language use of competent native speakers as evidences. He argued that to understand human verbal behaviour such as the creative aspects of language development and use, one must first postulate a genetic linguistic endowment, the assumption running counter Skinner's behaviourism.

Chomsky's critique of Skinner's methodology and basic assumptions paved the way for the cognitive revolution, the shift in American psychology between the 1950s through the 1970s from being primarily behavioural to being primarily cognitive. He focused on questions concerning the operation and development of innate structures for syntax capable of creatively organizing, cohering, adapting and combining words and phrases into intelligible utterances. He claimed that linguistic competence is the product of a species-specific innate language faculty, which is independent of other cognitive capacities (Radford et al 1999: 14). Chomsky established the role of mind in linguistics at the cost of physiological processes. His theory heralded the triumph of 'psyche' over 'physique'. 'Language knowledge is part of the speaker's mind; hence the discipline that studies it is part of psychology. Chomsky has indeed referred to that branch of human psychology known as linguistics.' (Cook and Newson, 1996: 37) 


\section{Linguistic Nativism:}

According to linguistic nativism, human infants have access to some specifically linguistic information that is not learned from linguistic experience. Linguistic nativists have threefold claim. First, part of language is unlearned and hence cannot be acquired by inductive methods. Second, language acquisition draws on an unlearned system of language. Third, there is a special component of the human mind which has the development of language as its key function, and no nonhuman species has anything of the sort.

Chomsky's theory of language is termed nativist, in the strongest sense of mentalism. Chomsky's nativism suggests that language is an innate faculty, that is, humans are born with a set of rules about language, referred to as UG. The UG is the basis upon which all human languages build. Chomsky makes it clear:

The language faculty has an initial state, genetically determined; in the normal course of development it passes through a series of states in early childhood, reaching a relatively stable steady state that undergoes little subsequent change, apart from the lexicon. To a good first approximation, the initial state appears to be uniform for the species. Adapting traditional terms to a special usage, we call the theory of the state attained its grammar and the theory of the initial state Universal Grammar (UG). (Chomsky, 1995: 14)

Children learn language as a normal course of development as they are facilitated by UG. When a child begins to listen to his/her parents, he/she will unconsciously recognise which kind of a language he/she is dealing with and he/she will set his/her grammar to the correct one - this is known as 'parameter setting'. He/she knows intuitively that there are some words that behave like verbs, and others like nouns, and that there is a limited set of possibilities as to their ordering within the phrase. This is not information that he is taught directly by the adults that surround him/her, but information that is given. This set of language learning tools, provided at birth, is referred to by Chomsky as the Language Acquisition Device (LAD). Akmajian et al (2010) elaborate on how children use LAD to acquire phonological, morphological and syntactic competence.

The evidence indicates that children, in fact, absorb a good number of sentences and phrases and abstract rules from them and create their own grammar which they then apply to create new utterances they have never heard before. Over the years from 2-7, when language is mastered, children constantly adjust their grammar until it matches that of the adult speaker population. This critical period between the ages of 2-7 suggests that first language learning, like walking, is an innate capacity of human beings triggered by a level of development more than feedback from the environment. That is, so long as a child hears a language - any language - when he/she reaches this critical period, he/she will learn it perfectly. Therefore, any child not hearing language during this period would not learn to speak. This is known as critical period hypothesis.

\section{Chomsky's Essentialism:}

Noam Chomsky has been called the intellectual ancestor of linguistic essentialism, which aims to identify the intrinsic properties of language per se. Linguistic essentialism is interested in postulating universals of human linguistic structures, unlearned but tacitly known, that permit and assist children to acquire human languages. It has a preference for finding surprising characteristics of languages that cannot be 
inferred from the data of usage, and are not predictable from human cognition or the requirements of communication.

According to Chomsky, the essence of language is its structural rudiment. His essentialism has several characteristics. These are discussed below.

\subsection{Competence, not Performance:}

As an essentialist, Chomsky distinguishes between competence and performance. Competence is the knowledge of language a tacit grasp of the structural properties of all the sentences of a language. Performance involves actual real-time use and may diverge radically from the underlying competence due to environmental disturbances and memory limitations.

Competence enables people to generate all possible grammatical sentences. Performance is the transformation of this competence into everyday speech. Chomsky proposed that linguistic theory should explain the mental processes that underlie the use of language. That is, the subject matter of linguistics will be competence, not performance.

\subsection{I-language, not E-language:}

Chomsky (1986) introduced two technical notions of language: E-language and I-language. ' $E$ ' stands for 'extensional' and 'external' and E-language refers to language data or corpus which is external to the mind. 'I' stands for 'individual', 'internal', and 'intensional', and I-language means internalized language - the properties of the mind of individuals who know them. (Chomsky, 1995: 15-16) As a generative essentialist sees it, I-language is a state of mind/brain. Chomsky rejects Elanguage as undeserving of study and suggests I-language as the only suitable object of study in linguistics. I-languages can and should be studied in isolation from their external environments. Chomsky says:

For $\mathrm{H}$ to know $\mathrm{L}$ is for $\mathrm{H}$ to have a certain I-language. The statements of the grammar are statements of the theory of mind about the I-language, hence structures of the brain formulated at a certain level of abstraction from mechanisms. (Chomsky, 1986: 23)

This branch of the study of language (generative grammar) is indeed marked by an absence of any role for community and culture ... There is nothing of any significance known, at least to me, about community and culture that relates to these questions about the nature of a certain biological system. (Chomsky 2000: 42)

This conclusion puts Chomsky in wrestling ring facing non-essentialists, who think that language is a social-functional or external phenomenon. Michael Dummett has thought language as a social custom, Esa Itkonen as social rules and David Lewis as social convention. Piaget and Vygotsky also laid the primary emphasis on the role of social or environmental factors in language development. Largely influenced by Wittgenstein, ordinary language philosophers $\mathrm{H}$. P. Grice, J. L. Austin and J. R. Searle postulated their pragmatic theories like implicatures, conversational maxims and speech acts based on the practical use of language (Levinson, 1983). In fact, 'there are various views about the nature of language and meaning that can be labelled externalist and Chomsky has been critical of them all' (Bezuidenhout, 2006: 129). His conviction even pitted him against descriptive linguistics of Leonard Bloomfield and structural linguistics of Ferdinand de Saussure. In his scientific capacity, Chomsky views language as a biological organ or device. As such, it's devoid of humour, metaphor, emotion, communicative intent, 
social meaning or anything else people normally think of as language (Knight, 2010: 22). Maher and Groves (1998: 59-60) noted that Chomsky's internalist view of language faced opposition from five fronts - anthropological linguistics, sociology, political economy, philosophy and humanistic.

\subsection{Universal Grammar:}

According to Chomsky, Universal Grammar (UG) is the system of principles, conditions, and rules that are elements or properties common to all languages - the essence of human language. All human beings share part of their knowledge of language. UG is their common possession regardless of which language they speak. The rules of UG provide the basic blueprint that all languages follow. (Chomsky, 1976: 29; Cook \& Newson, 1996: 1-2; Fromkin, Rodman and Hyams, 2007: 25) UG theory attempts to clarify the relatively quick acquisition of the mother tongue on the basis of minimum exposure to external input. Learning would be impossible without universal language-specific knowledge. Chomsky says:

It is reasonable to suppose that UG determines a set of core grammars and that what is actually represented in the mind of an individual even under the idealisation to a homogeneous speech community would be a core grammar with a periphery of marked elements and constructions. (Chomsky, 1982: 8)

Chomsky says that human babies are born with the core linguistic sense common to all language, which helps them to acquire any specific language from the environment. According to Chomsky, the language faculty is part of our biological endowment, and as such it is largely genetically determined. Neuropsychologist Eric Lenneberg in his Biological Foundations of Language (1967) lends support to
Chomsky's view. He says the capacity to learn a language is indeed innate, and, like many such inborn mechanisms, it is circumscribed in time. If a child does not learn a language before the onset of puberty, the child will never master language at all, as claimed in the critical period hypothesis.

The proposal of universal grammar puts Chomsky in the core of rationalist tradition. Chomsky's proposal bears an affinity with the concept of archetype theorized by noted Swiss psychiatrist Carl Jung. According to Jung, human beings are born with certain inherited modes of functioning rooted in collective unconscious, referred to as archetypes. Archetypes are conceived as innate neuropsychic centres possessing the capacity to initiate, control, and mediate the common behavioural characteristics and typical experiences of all human beings. According to Chomsky, although grammars differ from one another, their basic forms - deep structures are universal; that is, at the deepest neuropsychic level, there exists a universal or archetypal grammar, on which all individual grammars are based.

\section{Chomsky's Linguistic Reductionism:}

Chomsky virtually reduces language to its grammar. He says, 'A grammar of the language $\mathrm{L}$ is essentially a theory of $\mathrm{L}$ ' (Chomsky, 1957/2002: 49) and 'Grammar is best formulated as a self-contained study independent of semantics' (Ibid, 106). According to him, linguistics equates grammar, excluding the discussion of meaning. He regards meaning as secondary, so he disregards the social situation in which language is normally ised. For Chomsky, semantics and pragmatics are not a central part of the study of language and the study of meaning and reference and of the use of language should be excluded from 
the field of linguistics. Chomsky's syntax-semantics noninterface is recounted by Alexander Luria:

According to him, it is possible to determine whether or not a sentence is grammatical without regard to its semantic acceptability....Chomsky's approach made it possible to make progress in the formal syntactic analysis of sentences without becoming bogged down in semantic problems. (Luria, 1982: 121-22)

Chomsky posits a syntactocentric view of linguistic analysis and he says natural language consists of 'internalist computations'. This aspect of his reductionism has been elaborately explained in The Minimalist Program (1995). He also discusses the ability and desirability of reduction of linguistic knowledge to its mathematical basis in his article 'Mysteries of Nature: How Deeply Hidden' (2009).

\section{Conclusion:}

Chomsky's work in linguistics has had profound implications for modern psychology, philosophy and science. The branch of knowledge which we call 'biolinguistics' today took direct inspiration from him. For Chomsky, linguistics is a branch of cognitive psychology. Genuine insights in linguistics imply concomitant understandings of the aspects of mental processing and human nature. One consequence of such insights is that linguistics, psychology and philosophy are no longer to be regarded as separate and autonomous disciplines (Lyons, 1991: 125). Chomsky has placed linguistics at the core of studies of the mind. According to him, linguistic theory must account for universal similarities between all languages. His contribution to the cognitive sciences - fields that seek to understand how we think, learn, and perceive - emerges from his insightful theories. His unique philosophy of language has given linguistics a respectable place in the wider sphere of epistemology. Lyons (1991: 9-10) concludes: 'If it is now widely recognised as a branch of science which is worthwhile pursuing, not only for its own sake, but also for the contributions it can make to other disciplines, it is very largely due to Chomsky.' Chomsky is a champion of great advancement of knowledge in contemporary period.

\section{References:}

Akmajian, A., Demers, R., Farmer, A., \& Harnish, R., 2010. Linguistics: An Introduction to Language and Communication (6 $6^{\text {th }}$ edition), Cambridge, Massachusetts: MIT Press.

Baghramian, Maria, 1998, Modern Philosophy of Language, Washington: Counterpoint.

Bezuidenhout, Anne L., 2006, "Language as Internal”, in Lepore and Smith (eds.), The Oxford Handbook of Philosophy of Language, Oxford: Clarendon Press.

Chomsky, Noam, 1957/2002, Syntactic Structures, Berlin: Mouton de Gruyter.

Chomsky, Noam, 1965, Aspects of the Theory of Syntax, Cambridge, Massachusetts: MIT Press.

Chomsky, Noam, 1966, Cartesian Linguistics, New York: Harper and Row.

Chomsky, Noam, 1969, "Linguistics and Philosophy”, in Language and Philosophy: A Symposium, Sidney Hook, (ed.), New York: New York University Press, 51-94.

Chomsky, Noam, 1976, Reflections on Language, London: Temple Smith.

Chomsky, Noam, 1977, Language and Responsibility, New York: Pantheon Books. 
Chomsky, Noam, 1982, Lectures on Government and Binding, Dordrecht: Foris.

Chomsky, Noam, 1986, Knowledge of Language: Its Nature, Origin and Use, Westport, CT: Praeger.

Chomsky, Noam, 2000, The Architecture of Language, Oxford: Oxford University Press.

Chomsky, Noam, 2002, On Nature and Language, Cambridge: Cambridge University Press.

Chomsky, Noam, 2009, “The Mysteries of Nature: How Deeply Hidden?” in Journal of Philosophy, 106 (4): 167-200.

Chomsky, Noam, 2012, The Science of Language, Cambridge: Cambridge University Press.

Cook, V. J. \& Newson, Mark, 1996, Chomsky's Universal Grammar: An Introduction (2 ${ }^{\text {nd }}$ edition), Oxford: Blackwell Publishers.

D’Agostino, Fred, 1986, Chomsky's System of Ideas, Oxford: Oxford University Press.

Fromkin, V., Rodman, R. \& Hyams, N., 2007, Language: Nature, Psychology and Grammar Aspects, New Delhi: Wadsworth.

Harrison, Bernard, 1979, An Introduction to the Philosophy of Language, London: Macmillan.

Knight, Chris, 2010, “The Chomsky Enigma”, in Radical Anthropology, 4, 22-30.

Levinson, Stephen C., 1983, Pragmatics, Cambridge: Cambridge University Press.

Luria, Alexander R., 1982, Language and Cognition, New York: John Wiley and Sons.

Lycan, William G., 2008, Philosophy of Language: A Contemporary Introduction (second edition), New York: Routledge.
Lyons, John, 1991, Chomsky, London: Fontana Press.

Maher, John \& Groves, Judy, 1998, Introducing Chomsky, New York: Totem Books.

Pinker, Steven, 2007, The Stuff of Thought: Language as a Window into Human Nature, London: Penguin.

Radford, A., Atkinson, M., Britain, D., Clahsen, H. \& Spencer, A., 1999, Linguistics: An Introduction, Cambridge: Cambridge University Press.

Smith, Neil, 1999, Chomsky: Ideas and Ideals, Cambridge: Cambridge University Press.

Szabó, Zoltán Gendler, "Noam Chomsky”, in Ernest LePore (ed.), Dictionary of Modern American Philosophers, 1860-1960, Bristol, 2004.

Wise, Christopher, 2011, Chomsky and Deconstruction: The Politics of Unconscious Knowledge, New York: Palgrave Macmillan. 